\title{
Inclusion Exclusion Criterion Sponsor Defined Identifier
}

National Cancer Institute

\section{Source}

National Cancer Institute. Inclusion Exclusion Criterion Sponsor Defined Identifier. NCI

Thesaurus. Code C83300.

One or more sponsor defined characters used to name inclusion exclusion criteria. 